\title{
Alterations and Chromosomal Variants in the Ecuadorian Population
}

\author{
César Paz-y-Miño, Nadia Cumbal, Santiago Araujo, and Ma. Eugenia Sánchez
}

Instituto de Investigaciones Biomédicas, Facultad de Ciencias de la Salud, Universidad de las Américas, Avenida de los Granados y Colimes, Quito 1712842, Ecuador

Correspondence should be addressed to César Paz-y-Miño, cpazymino@udla.edu.ec

Received 23 March 2012; Accepted 30 May 2012

Academic Editor: Thomas Liehr

Copyright () 2012 César Paz-y-Miño et al. This is an open access article distributed under the Creative Commons Attribution License, which permits unrestricted use, distribution, and reproduction in any medium, provided the original work is properly cited.

Medical genetics is a field marked by fast progress. Even though it was at one point confined to a group of relatively rare diseases, today it has become a central component in the understanding of disorders and it is the subject of interest for all medical specialties. This paper, shares data on the chromosomal alterations and variations that have been diagnosed in Ecuadorian patients since 1998. A total of 2,636 individual cases have been analyzed by G-banding technique until February 2012. The present work shows this collection of data and the important findings that have appeared throughout these years in hopes that it can contribute to have a deeper understanding of the incidence of chromosomal aberrations and alterations in the Ecuadorian population.

\section{Introduction}

Medical genetics studies the variations of human inheritance when they are the origin of an abnormal conditions or disease. Such conditions can be often diagnosed at a gross scale by means of cytogenetic analysis. In Ecuador, this analytical discipline became better known by the early 90's when Varas (1990) showed the existence of a $0.25 \%$ of individuals with chromosomal alterations among 12,112 newborns in Quito [1]. Around the globe, the statistics show that the incidence of diseases with a genetic origin that becomes evident before the age of 25 is 53/1,000 [2]. Many factors can have a negative influence on an embryo's survival; however, chromosomal aberrations are among the most significant since they alter the expression of many genes in the earlier stages of development [3]. Some authors suggest that the prevalence of chromosome disorders at birth is higher in developing countries possibly due to the lack of family planning services and unavailability of prenatal among other reasons [4]. In fact, South America bears unique characteristics that may also influence the development of diseases as a result of geneenvironment interaction, characteristics such as ethnic diversity, structure and geographic location of populations, and a high frequency of exposure to environmental factors [5].
In the 1980s in Latin America and the Caribbean, the proportion of infant deaths attributable to congenital anomalies varied from approximately 2 to 27 per cent and ranked among the five leading causes of infant deaths in that region [6]. Since then, the study of the epidemiology of genetic disorders and congenital malformations is a high priority [3]. In 2010, National Institute of Statistics and Census (INEC) reported that congenital malformations and chromosomal anomalies in Ecuador occupy the twenty second (1.1\%) among the general causes of mortality in the Ecuadorian population [7]. Meanwhile, the ECLAMC report unveils that there are high frequencies of anotia/microtia and harelip among the major malformations diagnosed in Ecuadorian hospitals [5], likely related to high altitude. The present work shows information on chromosomal alterations and variants found during 13 years of cytogenetic services provided to Ecuadorian patients referred from various hospitals around the country.

\section{Materials and Methods}

A total of 2,636 individuals have been analyzed during the past 13 years. The corresponding karyotypes have been 
TABLE 1: Chromosomal autosomopathies in the registry.

\begin{tabular}{|c|c|c|}
\hline & Number & $\%$ \\
\hline Trisomy 9 (mosaic) & 2 & 0.2 \\
\hline Trisomy 13 & 14 & 1.6 \\
\hline Trisomy 13 (mosaic) & 1 & 0.1 \\
\hline Trisomy 18 & 19 & 2.2 \\
\hline Trisomy 18 (mosaic) & 1 & 0.1 \\
\hline Trisomy 19 & 2 & 0.2 \\
\hline Trisomy 19 (mosaic) & 1 & 0.1 \\
\hline \multicolumn{3}{|l|}{ Trisomy 21} \\
\hline Free trisomy & 674 & 78.6 \\
\hline Mosaic & 91 & 10.6 \\
\hline Isochromosome & 5 & 0.6 \\
\hline Translocation & 14 & 1.6 \\
\hline Translocation (mosaic) & 1 & 0.1 \\
\hline Trisomy 22 & 1 & 0.1 \\
\hline \multicolumn{3}{|l|}{ Partial trisomy } \\
\hline $4 p+$ & 2 & 0.2 \\
\hline $7 \mathrm{p}+$ & 1 & 0.1 \\
\hline $9 \mathrm{p}+$ & 1 & 0.1 \\
\hline $14 \mathrm{p}+$ & 3 & 0.3 \\
\hline $15 \mathrm{p}+$ & 3 & 0.3 \\
\hline $19 \mathrm{p}+$ & 2 & 0.2 \\
\hline $19 q+$ & 1 & 0.1 \\
\hline $21 \mathrm{q}+$ & 1 & 0.1 \\
\hline $22 \mathrm{p}+$ & 2 & 0.2 \\
\hline \multicolumn{3}{|l|}{ Partial monosomy } \\
\hline $5 p-$ & 4 & 0.5 \\
\hline $12 \mathrm{p}-$ & 1 & 0.1 \\
\hline $17 q-$ & 1 & 0.1 \\
\hline $13 q-$ & 3 & 0.3 \\
\hline $18 \mathrm{p}-$ & 1 & 0.1 \\
\hline Isochromosome 17 & 1 & 0.1 \\
\hline Ring chromosome 1 & 1 & 0.1 \\
\hline Ring chromosome 9 & 1 & 0.1 \\
\hline Ring chromosome 15 & 1 & 0.1 \\
\hline inv (9) mosaic & 1 & 0.1 \\
\hline Add (8) (p23) & 1 & 0.1 \\
\hline Total & 858 & 100.0 \\
\hline
\end{tabular}

observed by the G-banding technique during the period of 1998-2012. The individuals come from many places around Ecuador and have been referred to the Institute by primary care centers in order to obtain a cytogenetic analysis. The diagnoses were classified according to the International System for Human Cytogenetic Nomenclature [8] and organized into three tables that show the number and percentage of cases with chromosomal autosomopathies, chromosomal gonosomopathies, and chromosomal variants and polymorphisms, respectively. The latest cases of gonosomopathies have been also analyzed by the FISH technique with the CEP X/Y DNA Probe Kit from Abbott Molecular and SRY specific primers.
TABLE 2: Chromosomal gonosomopathies in the registry.

\begin{tabular}{lcc}
\hline & Number & $\%$ \\
\hline Turner syndrome & 132 & 40.1 \\
$\quad$ Monosomy & 109 & 33.1 \\
Mosaic & 6 & 1.8 \\
Isochromosome & 8 & 2.4 \\
Isochromosome (mosaic) & 1 & 0.3 \\
$\quad$ Ring (mosaic) & 3 & 0.9 \\
Trisomy X & 3 & 0.9 \\
$\quad$ Mosaic & 6 & 1.8 \\
Fra (X) (q27.3) & 17 & 5.2 \\
Klinefelter syndrome & 4 & 1.2 \\
$\quad$ Mosaic & 7 & 2.1 \\
47,XYY & 4 & 1.2 \\
48,XXYY & 1 & 0.3 \\
49,XXXXY & & \\
Disorders of sex development & 6 & 1.8 \\
Female pseudohermaphroditism & 17 & 5.2 \\
Male pseudohermaphroditism & 2 & 0.6 \\
Mixed gonadal dysgenesis & 1 & 0.3 \\
Pure gonadal dysgenesis & 2 & 0.6 \\
Ambiguous genitalia & 329 & 100.0 \\
\hline Total & & \\
\hline
\end{tabular}

\section{Results}

As previously mentioned, the following tables show our findings classified in four different tables as chromosomal autosomopathies (Table 1), chromosomal gonosomopathies (Table 2), and translocations, chromosomal variants, and polymorphisms (Table 3). It can be noted that there is an unusual high percentage of Down syndrome mosaicism and Yqh+ polymorphism.

\section{Discussion}

Some of the most frequent clinic alterations that suggest the need for chromosomal analysis are mental retardation, short stature, infertility, and miscarriages, among others. The latest data published by ECLAMC reports that the overall percentage of malformations is $2.7 \%$ and in Ecuador, this percentage is $1.4 \%$ [9]. It has been reported that numerical and structural chromosomal abnormalities produce about 4$28 \%$ of all mental retardation cases. The severity of mental retardation and the presence of congenital anomalies in these cases increase the diagnostic significance of chromosome abnormalities [10]. Regarding mental retardation, it has been reported that numerical anomalies affect autosomes (6.5\%) more frequently than sex chromosomes (0.4\%). Also, numerical autosomal anomalies are mostly detected in individuals with more severe mental retardation [11]. Because of this, chromosome analysis of individuals with one or more clinical manifestations related to mental development has been a highly important consideration in the making of the present registry of disabilities in Ecuador. Trisomy 
TABLE 3: Translocations and variants in the registry.

\begin{tabular}{lccccc}
\hline Translocations & Number & Translocations & Number & Variants and polymorphisms & Number \\
\hline $\mathrm{t}(1 ; 20)$ & 1 & $\mathrm{t}(6 ; 7)$ & 2 & $1 \mathrm{qh}+$ & 2 \\
$\mathrm{t}(2 ; 8)$ & 1 & $\mathrm{t}(7 ; 10)$ & 1 & $9 \mathrm{qh}+$ & $15 \mathrm{ps}+$ \\
$\mathrm{t}(2 ; 12)$ & 2 & $\mathrm{t}(13 ; 14)$ & 3 & $16 \mathrm{qh}+$ & 1 \\
$\mathrm{t}(2 ; 18)$ & 2 & $\mathrm{t}(13 ; 15)$ & 2 & Yqh+ & 1 \\
$\mathrm{t}(4 ; 11)$ & 3 & $\mathrm{t}(\mathrm{X} ; 8)$ & 3 & Yqh- & 23 \\
$\mathrm{t}(5 ; 14)$ & 5 & $\mathrm{t}(\mathrm{X} ; 21)$ & 1 & Total & 4 \\
\hline & Total & 26 & \\
\hline
\end{tabular}

21 is the most common aneuploid condition appearing in approximately 1 out of every 800 to 1,000 live births [12]. According to the Latin-American Collaborative Study of Congenital Malformations ECLAMC (1982-2001), its incidence in Latin American countries like Chile is of 2.2 in every 1,000 newborns while, in Colombia, the condition appears in 15 out of every 10,000 [5]. This Trisomy is also the most frequent autosomal alteration found in our registry with $674(78.19 \%)$ cases. Other chromosomal variants of chromosome 21 were found in less percentage (Table 1). Additionally, Down syndrome mosaicism was present in $10 \%$ of the affected cases, a percentage remarkably high in comparison to the reported percentage of $2-4 \%$ [12]. This could be explained by the altitude at which Quito and peripheral towns are geographically located since these are places where most of our samples come from [13]. In fact, the ECLAMC showed higher frequencies of birth defects in populations living in high altitudes than the populations at sea level. Nonetheless, there are other factors that could contribute to the etiology of congenital anomalies in these regions [14-16]. The teratogenicity of hypoxia in mammals was demonstrated in an experiment in 1952 where pregnant mice placed in a low-pressure chamber with reduced oxygen tension gave birth to progeny with birth defects such as anencephaly, cleft palate, and cryptorchidism, among others [17]. Additionally, authors have produced trisomic and triploid embryos by mating hamster females and submitting them to low-pressure atmosphere and hypoxic conditions [18]. The association between congenital anomalies and high altitude has been noted in a number of studies that refer to craniosynostosis, cleft lip, congenital heart disease, neural tube defects, and so forth [16]. Also, studies in South America have concluded that high altitude in Ecuador is associated not only to the occurrence of low birth weight and intrauterine growth retardation regardless of socioeconomic status [19], but it is also a risk factor in the development of microtia and cleft palate [20-22]. In this study, we show that Down syndrome mosaicism is present in an unusually high percentage in the Andean zones of Ecuador. Although other variables such as maternal age and ethnicity should be addressed, we suggest that high altitude may also be related to this uncommon incidence as an epigenetic factor yet to be fully studied. In Ecuador, the incidence found is 1 of every 526 live births, which is a remarkable fact about the chromosomal constitution of our population [1]. This syndrome displays some developmental abnormalities and clinical characteristics that are normally observed with aging [23] including craniofacial dysmorphy, cardiovascular defects (40 to $50 \%$ incidence of congenital heart disease) [24], and learning disabilities [25]. Additionally, those affected present a higher incidence of leukemia (10-20 fold) [26]. Because of its prevalence and clinical importance, Down syndrome has a special relevance in medicine practice and in human biology. Therefore, its chromosomal characterization will offer a better knowledge of the evolution and the prognosis of the affected individuals besides guaranteeing the proper genetic counseling of couples at risk and the population in general. In Ecuador and other countries, there is an absence of basic information regarding individuals with Down syndrome. Thus, some authors highlight the importance of developing a Down syndrome registry, research database, and biobank that can be available to the affected individuals, families, medical care providers, government, and funding sources in order to promote and facilitate the research that focuses on this condition [27]. Although less common, the same attention is needed for other autosomal abnormalities found in our registry such as Trisomy $13(1.74 \%)$ and Trisomy $18(2.32 \%)$, as partial Trisomy and monosomy. The registry also found some interesting autosomal abnormalities such as isochromosomes of the 21 pair and a translocation between chromosomes 2 and 8.

In relation to sex chromosome abnormalities, Turner syndrome is the most frequent alteration found in our registry with a percentage of 77.7. This syndrome is one of the most frequent genetic disorders and affects 1 out of every 2,500 live female births. The main clinical features of Turner syndrome are short stature, low hair implantation, ovarian dysgenesis accompanied by estrogen deficit, otitis, thyroid dysfunction, hypertension, high risk of cardiovascular mortality, and other abnormalities of different levels of severity $[28,29]$. We found one case of mosaicism with $46, \mathrm{XY} / 45$, X karyotype belonging to a girl that had primary amenorrhea, uterus, and ovaries infertile. Published data has shown that the presence of Y-chromosome material in patients with Turner syndrome represents a risk factor for the development of gonadoblastoma. Y-chromosome mosaicism is observed in 5\% of Turner patients; thus, the detection of this chromosome by cytogenetic or molecular means is very valuable [30]. Also, our registry shows a $6 \%$ of Klinefelter syndrome cases and fewer percentages of other sex chromosome anomalies (Table 2). Additionally, the Yqh+ polymorphism was found in $12 \%$ of men (Table 3 ), and 
there were 134 cases that showed chromosomal fragility. The early diagnostic of chromosome abnormalities is essential for guaranteeing an adequate treatment and management of the individuals with the purpose of having the best possible social integration. We consider that it is fundamental to have a National Registry in Ecuador that incorporates a broad range of conditions, including chromosomal abnormalities and findings. This knowledge can be invaluable for the elaboration of appropriate courses of action that promote genetics studies and prenatal diagnosis in the Ecuadorian population.

\section{Strengths}

Population. The Ecuadorian population offers unique characteristics that favor the study of gene-environment interactions. Features such as ethnic diversity, geographic location at high altitude, environmental diversity, socioeconomic differences, and poor control of exposure to toxic compounds make of our population a very interesting and novel source of information.

Information. Cytogenetic findings in the Ecuadorian population such as the ones presented in this paper have not been published previously elsewhere. Thus, the information offered shows noteworthy data and tendencies.

\section{Pitfalls}

Sample. The data is based on cases that have generally been referred to the institute by primary care centers where the individuals have been given medical attention because of suspicion or evidence of a medical condition of genetic origin. Therefore, this is not a random sample of the population.

Variables. Although it isn't one of the objectives of the present paper, our study falls short on showing the association of the cytogenetic findings with other variables such as maternal age, socioeconomic status, and ethnicity.

\section{References}

[1] C. Varas, "Malformaciones congénitas en recién nacidos y estudio cromosómico en polimalformados," Unpublished manuscript, Pontificia Universidad Católica del Ecuador, Quito, Ecuador, 1990.

[2] A Bonino, P Gómez, L Cetraro, G Etcheverry, and W. Pérez, "Malformaciones congénitas: incidencia y presentación clínica," Archivos de Pediatría del Uruguay, vol. 77, no. 3, pp. 225-228, 2006.

[3] S. Kofman-Alfaro and V. Penchaszadeh, "Community genetic services in Latin America and regional networks on medical genetics," Recommendations of the World Health Organization Consultation on Medical Genetics in Latin America, Porto Alegre, Brazil, 2003, http://www.bvs.org.ar/ genetica/pdf/WHO_recomendations.pdf.

[4] V. B. Penchaszadeh, "Preventing congenital anomalies in developing countries," Community Genetics, vol. 5, no. 1, pp. 61-69, 2002.
[5] G. Montalvo, A. Camacho, M. Toscano et al., "Frecuencia de malformaciones congénitas en hospitales ecuatorianos de la Red ECLAMC Periodo de Junio 2001-2005," Cambios, vol. 5, no. 9, pp. 1-13, 2005.

[6] A. Rosano, L. D. Botto, B. Botting, and P. Mastroiacovo, "Infant mortality and congenital anomalies from 1950 to 1994: an international perspective," Journal of Epidemiology and Community Health, vol. 54, no. 9, pp. 660-666, 2000.

[7] INEC, "Principales causas de mortalidad general. Año 2010. Lista corta de agrupamiento de causas de muerte (L.C. CIE-10)," INEC: Estadísticas de Nacimientos y Defunciones (Generales y Fetales), 2010, http://www.inec.gob.ec/estadisticas/index.php?option $=$ com_remository $\&$ Itemid $=\&$ func $=$ startdown\&id $=156 \&$ lang $=$ es\&TB_iframe $=$ true\&height $=250 \&$. width $=800$.

[8] L. G. Shaffer, M. L. Slovak, and L. J. Campbell, ISCN 2009: An International System for Cuman Cytogenetic Nomenclature, Karger, Basel , Switzerland, 2009.

[9] J. Nazer and L. Cifuentes, "Malformaciones congénitas en Chile y Latino América: Una visión epidemiológica del ECLAMC del período 1995-2008," Revista Médica de Chile, vol. 139, no. 1, pp. 72-78, 2011.

[10] C. J. Curry, R. E. Stevenson, D. Aughton et al., "Evaluation of mental retardation: recommendations of a consensus conference," American Journal of Medical Genetics, vol. 72, no. 4, pp. 468-477, 1997.

[11] C. D. M. van Karnebeek, M. C. E. Jansweijer, A. G. E. Leenders, M. Offringa, and R. C. M. Hennekam, "Diagnostic investigations in individuals with mental retardation: a systematic literature review of their usefulness," European Journal of Human Genetics, vol. 13, no. 1, pp. 6-25, 2005.

[12] L. B. Jorde, J. C. Carey, M. J. Bamshad, and R. L. White, Medical Genetics, Mosby, St. Louis, Mo, USA, 2006.

[13] C. Paz-y-Miño, M. Vega, M. Sanchez, and P. Leone, "Consejo Genético," Metro Ciencia, vol. 121, no. 2, pp. 5-9, 2003.

[14] E. E. Castilla and I. M. Orioli, "Prevalence rates of microtia in South America," International Journal of Epidemiology, vol. 15, no. 3, pp. 364-368, 1986.

[15] J. S. Lopez-Camelo and I. M. Orioli, "Heterogeneous rates for birth defects in Latin America: hints on causality," Genetic Epidemiology, vol. 13, no. 5, pp. 469-481, 1996.

[16] E. E. Castilla, J. S. Lopez-Camelo, and H. Campaña, "Altitude as a risk factor for congenital anomalies," American Journal of Medical Genetics, vol. 86, no. 1, pp. 9-14, 1999.

[17] T. H. Ingalls, F. H. Curley, and R. A. Prindle, "Experimental production of congenital anomalies; timing and degree of anoxia as factors causing fetal deaths and congenital anomalies in the mouse," New England Journal of Medicine, vol. 247, no. 20, pp. 758-768, 1952.

[18] T. Shimada, G. Watanabe, and T. H. Ingalls, "Trisomies and triploidies in hamster embryos: induction by low-pressure hypoxia and $\mathrm{pH}$ imbalances," Archives of Environmental Health, vol. 35, no. 2, pp. 101-105, 1980.

[19] J. S. López Camelo, H. Campaña, R. Santos, and F. A. Poletta, "Effect of the interaction between high altitude and socioeconomic factors on birth weight in a large sample from South America," American Journal of Physical Anthropology, vol. 129, no. 2, pp. 305-310, 2006.

[20] F. González-Andrade, R. López-Pulles, V. H. Espín, and C. Paz-Y-Mio, "High altitude and microtia in Ecuadorian patients," Journal of Neonatal-Perinatal Medicine, vol. 3, no. 2, pp. 109-116, 2010.

[21] A. W. James, S. A. Brugmann, A. L. Carre, M. Jame, and M. T. Longaker, "Invited commentary: Discharge prevalence estimation, high altitude and microtia in Ecuadorian patients," Journal of Neonatal-Perinatal Medicine, vol. 3, no. 2, pp. 85-86, 2010. 
[22] F. A. Poletta, E. E. Castilla, I. M. Orioli, and J. S. LopezCamelo, "Regional analysis on the occurrence of oral clefts in South America," American Journal of Medical Genetics A, vol. 143, no. 24, pp. 3216-3227, 2007.

[23] M. A. Kusters, R. H. Verstegen, and E. de Vries, "Down syndrome: is it really characterized by precocious immunosenescence?" Aging and Disease, vol. 2, no. 6, pp. 538-545, 2011.

[24] Z. Elmagrpy, A. Ravani, A. Shah, E. Habas, and E. H. Aburawi, "Down syndrome and congenital heart disease: why the regional difference as observed in the Libyan experience?" Cardiovascular Journal of Africa, vol. 22, no. 6, pp. 306-309, 2011.

[25] I. Khan, S. Malinge, and J. D. Crispino, "Myeloid leukemia in Down syndrome," Critical Reviews in Oncogenesis, vol. 16, no. 1-2, pp. 25-36, 2011.

[26] F. Mitelman, S. Heim, and N. Mandahl, "Trisomy 21 in neoplastic cells," American Journal of Medical Genetics, no. 7, pp. 262-266, 1990.

[27] L. L. McCabe and E. R. B. McCabe, "Down syndrome: issues to consider in a national registry, research database and biobank," Molecular Genetics and Metabolism, vol. 104, no. 1-2, pp. 1012, 2011.

[28] M. Berková, Z. Berka, and Z. Krcová, “Turner's syndrome requires multidisciplinary approach," Vnitr Lek, vol. 55, no. 5, pp. 501-505, 2009.

[29] C. de Araùjo, B. B. Galera, M. F. Galera, and S. F. de Medeiros, "Clinical and cytogenetic aspects of the Turner syndrome in the Brazilian Western region," Revista Brasileira de Ginecologia e Obstetricia, vol. 32, no. 8, pp. 381-385, 2010.

[30] A. Sallai, J. Sólyom, M. Dobos et al., "Y-chromosome markers in Turner syndrome: screening of 130 patients," Journal of Endocrinological Investigation, vol. 33, no. 4, pp. 222-227, 2010. 

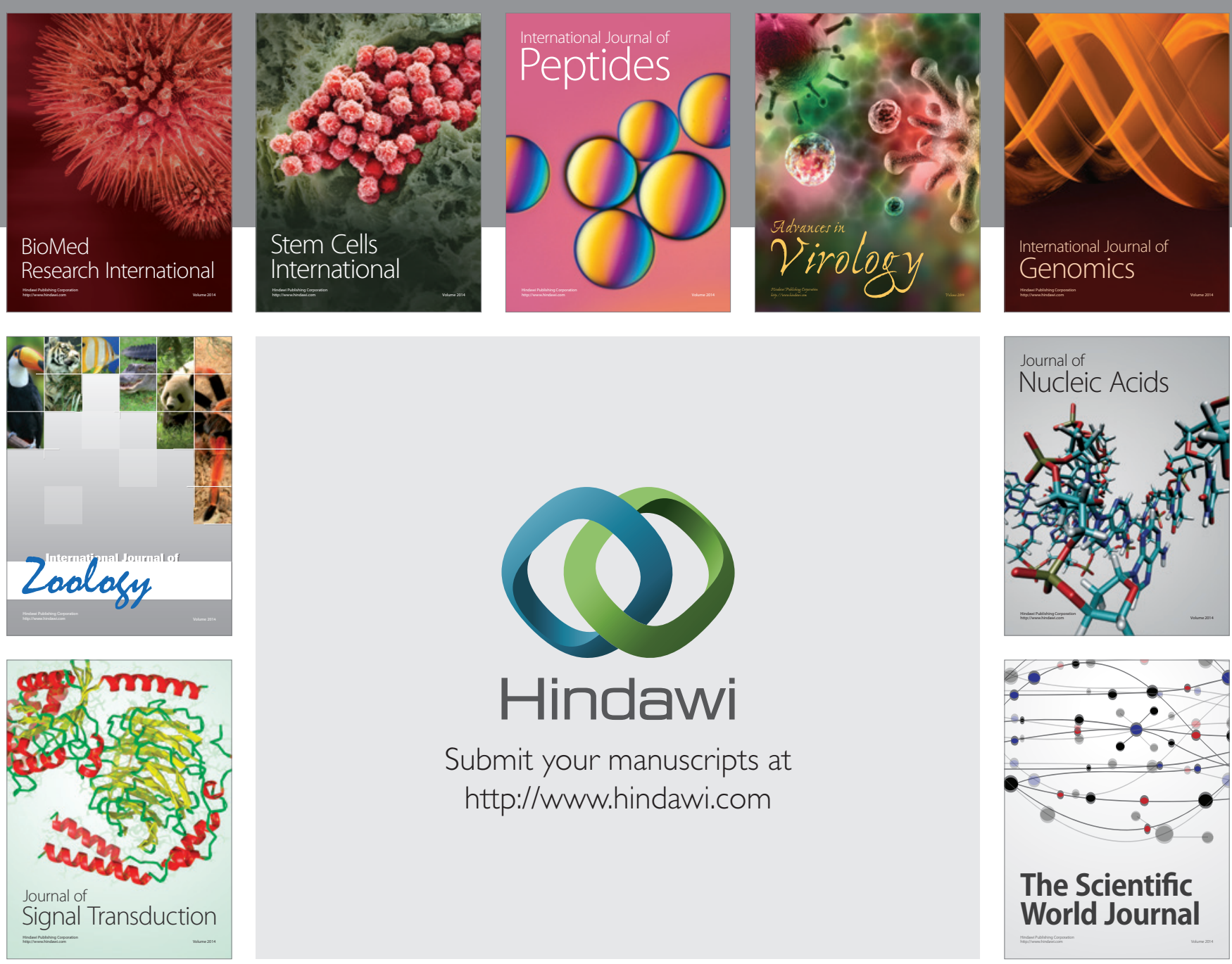

Submit your manuscripts at

http://www.hindawi.com
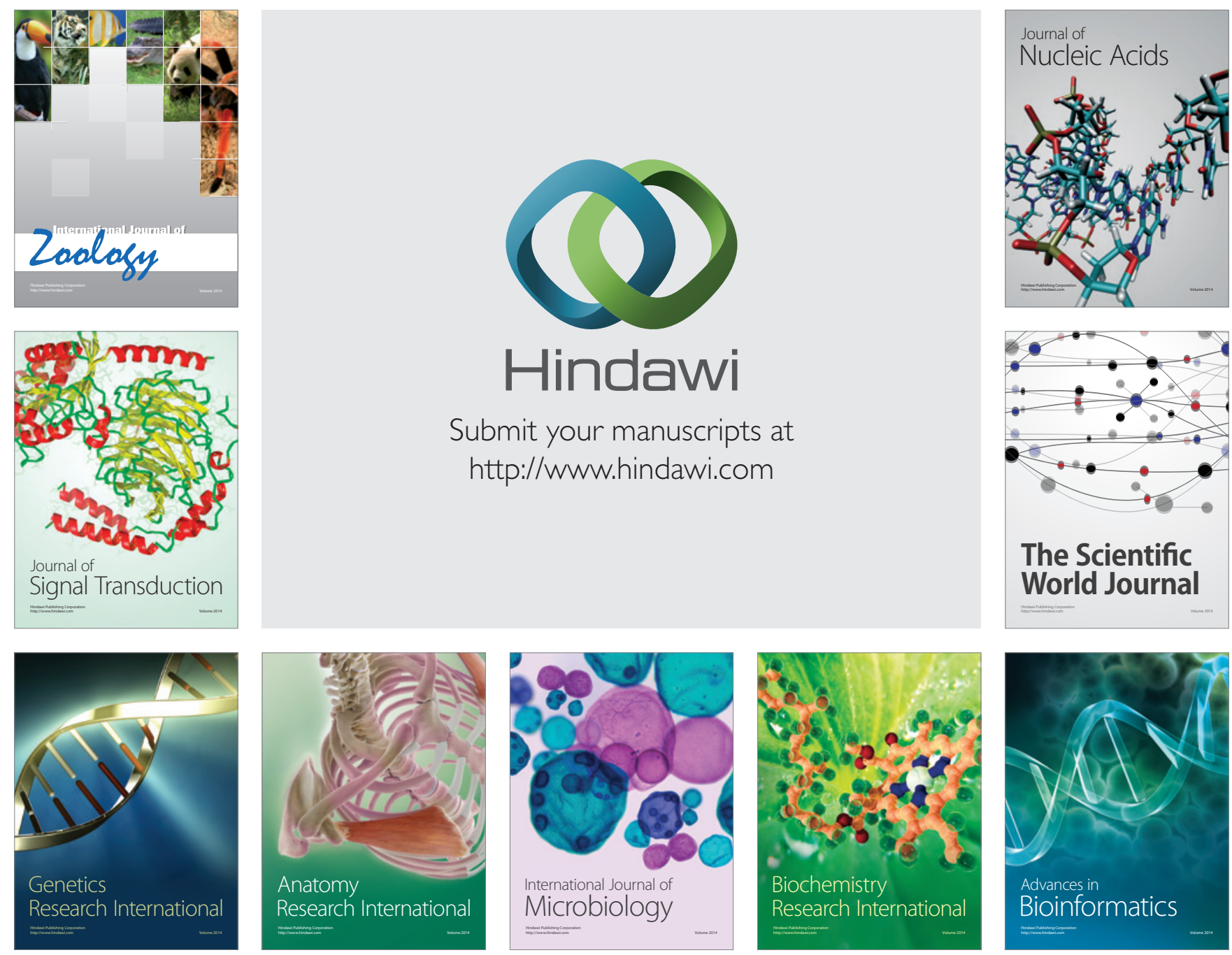

The Scientific World Journal
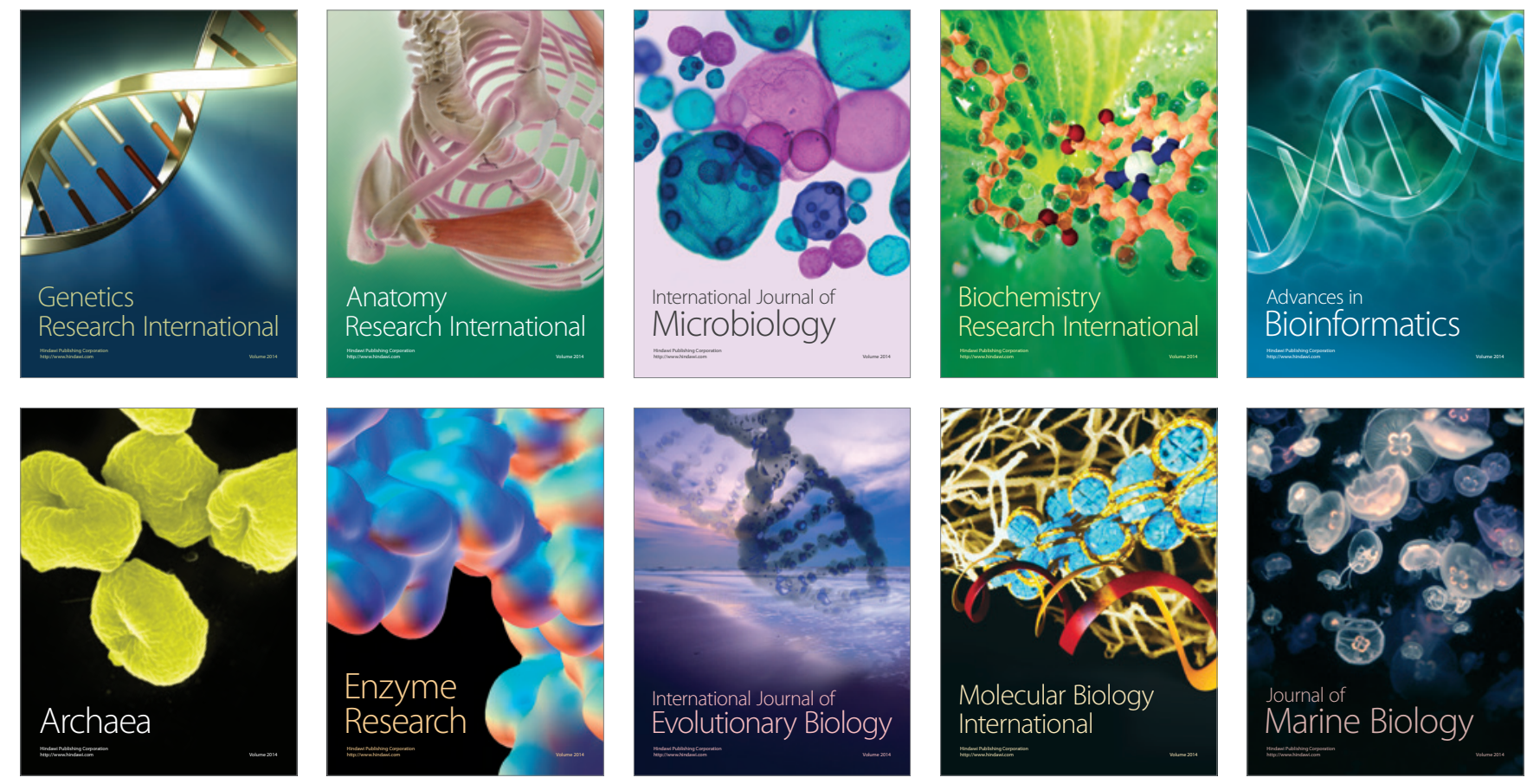